\title{
Projetar sobre projetos: currículo e ensino de História
}

\section{Design on projects: curriculum and History teaching}

\author{
Antonio Simplicio de Almeida Neto*
}

\begin{abstract}
RESUMO
Contra as evidências que entendem a educação escolar como um produto e os professores como figuras acessórias para a reprodução de propostas curriculares alienígenas, esse artigo propõe discutir possibilidades de projetos curriculares para o ensino de História na educação básica tomando por referência documentos produzidos por graduandos de Licenciatura em História ao pesquisar elementos da cultura escolar, a saber, os diferentes sujeitos escolares, os discursos, as práticas e os rituais, a cultura material e a arquitetura escolar (VIÑAO-FRAGO, 2007). Retomamos o entendimento de Marc Bloch (2001), para quem, o ofício do historiador, e do professor de História, por conseguinte, implica em posicionamento criativo, uma vez que pressupõe movimento, transformação e renovação. Tal postura se coaduna com o debate em torno da cultura escolar que toma a instituição escolar como produtora de cultura e não mera reprodutora de culturas que lhe são exteriores. Consideramos estar em jogo a relação entre projeto e destino (ARGAN, 2004): seguir o desígnio dito e decidido por outrem e efetuar o produto educacional, consumando a tão criticada fragmentação entre os criadores e executores ou projetar, tomando para si o desígnio, o desenho da aula de História.
\end{abstract}

Palavras-chave: Ensino de História. Currículo. Cultura escolar. Projetos.

\begin{abstract}
Against the evidences that understand the school education as a product and teachers as accessory figures for the reproduction of alien curricular proposals, this paper proposes to discuss possibilities of curricular projects
\end{abstract}

* Universidade Federal de São Paulo, Departamento de História, Guarulhos, São Paulo, Brasil. E-mail: asaneto@unifesp.br - https://orcid.org/0000-0002-0066-5067 
for the teaching of history in basic education, taking as reference documents produced by undergraduate sit-in-history students when researching elements of school culture, namely, the different school subjects, the discourses, practices and rituals, material culture and school architecture (VIÑAO-FRAGO, 2007). We return to the understanding of Marc Bloch (2001), for whom, the office of the historian, and the teacher of History, therefore, implies creative positioning, since it presupposes movement, transformation and renewal. Such a position is in line with the debate around the school culture that takes the school institution as producer of culture and not mere reproducer of cultures that are external to it. We consider the relation between project and destiny (ARGAN, 2004) to be at stake: to follow the established planned and decided by others and to accomplish the educational product, consummating the much criticized fragmentation between creators and executors or to project, taking the plan for themselves, the design of history class.

Keywords: History Teaching. Curriculum. School Culture. Projects.

"Teu fogo prometeico se resume à cabeça de um fósforo"

(Haroldo de Campos - Finismundo)

Em tempos de propostas curriculares unificadas, base curricular, sistemas apostilados, sistemas de avaliação, gratificação por produtividade, ranking de escolas, produtos educacionais e toda sorte de procedimentos que apontam para a padronização do ensino, parece despropositado propor atos criativos - poeisis no ensino de História. O cerco vai se fechando, com formas as mais sofisticadas e intrincadas de controle de todas as etapas do processo educativo, passando pelas definições de conteúdos e das atividades pedagógicas, pela elaboração, produção e distribuição de materiais didáticos, pelos processos avaliativos de professores e de alunos e sua premiação e/ou certificação, pelos modelos de gestão e de gerenciamento.

Tidas como inevitáveis, tais concepções e seus pressupostos, querem se tornar hegemônicos, de modo que as vozes contrárias a esse modelo e seus procedimentos soam anacrônicas. Vozes inauditas para ouvidos moucos.

Seleção de conteúdos feita por professores, criação de materiais didáticos, elaboração de projetos pedagógicos, observação da realidade escolar, avaliação qualitativa, relação teoria/prática, são discursos cada vez menos escutados e lidos, soando como simulacros. Parece ter se tornado líquido e certo que a educação é um produto como outro qualquer e que sujeitos exteriores à escola é que devem determinar o que vai dentro da sala de aula. 
No ensino de História a percepção não é diferente, haja vista a intensa polêmica observada na imprensa e nos meios acadêmicos, desencadeada pelos debates sobre as diferentes versões da Base Comum Curricular Nacional (BNCC), que orbitou quase que exclusivamente em torno de quais conteúdos (América ou Europa, índios ou gregos, negros ou egípcios, história cultural ou história social) seriam os mais adequados a figurar entre aqueles que as crianças e jovens deveriam aprender em todo o país. Curiosamente não foi observada grande celeuma sobre os princípios e pressupostos que fundamentam a existência de um currículo único para o país, sugerindo haver certa conformidade sobre tal ideia.

O que está em jogo, ao que se observa, é a relação entre projeto e destino (ARGAN, 2004). Parece ter havido um súbito consenso de que o professor é mesmo incapaz de pensar e criar sua aula, de selecionar os conteúdos para suas turmas e séries, de organizar seu tempo de aula, de propor e executar projetos em acordo com as diferentes realidades sócio históricas do país, de inventar materiais didáticos ou dispor como melhor lhe aprouver dos já existentes, de optar pelas metodologias mais adequadas, de inovar com novas abordagens, de fazer escolhas frente ao imponderável e às precariedades do cotidiano escolar. Dispensa dizer, mas nunca é demais, que as condições adversas da realidade profissional, dos baixos salários às salas de aula superlotadas, confluem para um deserto de desejos e de criação. De todo modo, caberia ao professor, nesse concerto tácito, seguir o desígnio dito e decidido por outrem e efetuar o produto educacional, consumando a tão criticada fragmentação entre os que criam e os que executam.

Nesse artigo, busco olhar entre os escombros da evidência e do consenso, projetar sobre projetos e suas implicações para o ensino de História, tomando o conceito de cultura escolar como mote da construção do saber histórico escolar e da formação de professores dessa disciplina.

Com esse intento procedemos a discussão do conceito de cultura escolar e seus elementos, assim como suas possibilidades para a investigação historiográfica e pedagógica. Para essa análise, lançamos mão de um corpus documental constituído fundamentalmente por relatórios e projetos de interação elaborados por graduandos de História nos anos de 2012 e 2014 junto a escolas da rede pública de ensino, aspectos que apresentaremos mais adiante, tomados como exercício da investigação densa da realidade escolar e de elaboração de propostas de ensino, aspectos centrais quando se deseja tomar para si o desígnio, o desenho da aula de História. 


\section{Cultura escolar, currículo e projeto}

No clássico livro Apologia da História ou O Ofício do Historiador, lemos que para Marc Bloch (2001, p. 47) a História é "um esforço para o conhecer melhor: por conseguinte, uma coisa em movimento" e, ainda, que "o conhecimento do passado é uma coisa em progresso, que incessantemente se transforma e aperfeiçoa" (BLOCH, 2001, p. 75). Tomando essa assertiva como referência, temos que o saber histórico implica num posicionamento criativo daquele que busca esse conhecimento, uma vez que pressupõe movimento, transformação e renovação.

A não ser que tomemos como premissa a ideia de que o professor de História da Educação Básica proceda a uma mera "transposição didática" do "saber sábio" acadêmico (CHEVALLARD, 2005) e esteja numa posição inferior na hierarquia de conhecimentos, também desse profissional deveríamos esperar uma postura criadora e criativa, seja porque possui uma formação acadêmica que o tornaria capaz de dialogar com conhecimento histórico acadêmico, mas também, fundamentalmente, porque a instituição escolar onde atua produz um saber que lhe é próprio, não estando reduzida à condição de reprodutora de uma cultura exterior.

Contrário, portanto, às vozes que esperam um professor de História resignado cumpridor de seu destino, consideramos particularmente instigante recuperarmos a proposição de Argan (2004) que, ao discutir arte e arquitetura (num longínquo 1964), apontava para a importância de se projetar contra:

Não se projeta nunca para, mas sempre contra alguém ou alguma coisa: contra a especulação imobiliária e as leis ou as autoridades que a protegem, contra a exploração do homem pelo homem, contra a mecanização da existência, contra a inércia do hábito e do costume, contra os tabus e a superstição, contra a agressão dos violentos, contra a adversidade das forças naturais; sobretudo, projeta-se contra a resignação ao imprevisível, ao acaso, à desordem, aos golpes cegos dos acontecimentos, ao destino. Projeta-se contra a pressão de um passado imodificável, para que sua força seja impulso e não peso, senso de responsabilidade e não complexo de culpa. Projeta-se contra algo que é, para que mude; não se pode projetar para algo que não é; não se projeta para aquilo que será depois da revolução, mas para a revolução, portanto contra todo tipo e modo de conservadorismo (ARGAN, 2004, p. 53). 
Seguindo essa asserção, teríamos um professor de História "contra" a resignação ao acaso e ao conservadorismo, contra a inércia e os tabus. Tal postura implica agência, disposição para ir ao encontro do destino e projetar contra. Contra a tradição formativa instaurada com a LDB n ${ }^{\circ}$ 5692/71, "afirmando a distinção entre bacharelado e licenciatura, produzindo dentro dos processos formativos do ofício do historiador uma alienação. (...) os professores passam a ser transmissores do conhecimento, alienados dos processos de sua produção e circulação" (TOLEDO; COSTA, 2014, p. 15); contra a formação precária e as precariedades da realidade em que atuam; contra a padronização e o controle das práticas, que se travestem de novas tendências da educação; contra os simulacros da retórica pedagógica; contra o desencanto gerado pela lógica do consumo aplicada à educação; contra o imobilismo e o conformismo que se desdobram em práticas inócuas e estéreis.

No entendimento aqui adotado, a reflexão sobre cultura escolar apresentase como possibilidade especialmente fecunda para a construção de projetos que ensejem novas práticas no ensino de História. Surgido no final da década de 1980, no âmbito das discussões sobre história das disciplinas escolares (CHERVEL, 1990) e currículo (FORQUIN, 1992), o conceito de cultura escolar foi amplamente utilizado em diversas áreas das pesquisas educacionais, tais como Sociologia, Psicologia, Filosofia, Didática e, notadamente, em História da Educação (FARIA FILHO et al., 2004, p. 142), em trabalhos sobre o cotidiano escolar, materialidade escolar, organização do tempo e do espaço escolares, arquitetura escolar, saberes e práticas escolares, métodos e apropriações, diferentes sujeitos escolares, etc.

Aos professores de História, tanto em seu processo de formação, como apontado por Toledo e $\operatorname{Costa}^{1}$ (2014, p. 19), como em seu exercício profissional, a adoção dessa perspectiva possibilitaria refletir historicamente sobre a própria cultura escolar em que estão inseridos, observando as práticas, os saberes, as representações, os materiais didáticos, os códigos e sujeitos, colocando-se, portanto, em perspectiva história.

A definição mais frequentemente utilizada de cultura escolar é a proposta por Dominique Julia, da qual destacamos o excerto:

(...) um conjunto de normas que definem conhecimentos a ensinar e condutas a inculcar, e um conjunto de práticas que permitem a transmissão desses conhecimentos e a incorporação desses comportamentos; normas

1 No referido texto, Toledo e Costa (2014) discutem a proposta curricular do curso de História da Universidade Federal de São Paulo, UNIFESP. 
e práticas coordenadas a finalidades que podem variar segundo as épocas (finalidades religiosas, sociopolíticas ou simplesmente de socialização). Normas e práticas não podem ser analisadas sem se levar em conta o corpo profissional dos agentes que são chamados a obedecer a essas ordens e, portanto, a utilizar dispositivos pedagógicos encarregados de facilitar sua aplicação, a saber, os professores primários e os demais professores. Mas, para além dos limites da escola, pode-se buscar identificar em um sentido mais amplo, modos de pensar e de agir largamente difundidos no interior de nossas sociedades, modos que não concebem a aquisição de conhecimentos e de habilidades senão por intermédio de processos formais de escolarização (JULIA, 2001, p. 10).

Para Julia (2001), no próprio processo de escolarização de determinadas práticas, conhecimentos e normas, historicamente variáveis, se constituem e são internalizados, conformando certa cultura escolar observável nos modos de pensar e agir tão característicos desse meio e que acabam por ultrapassar os muros da escola se irradiando pela sociedade. Esse autor explora muito apropriadamente o uso desse conceito para os estudos de História da Educação em perspectiva sociocultural, frente aos estudos que muito frequentemente desprezaram "as resistências, as tensões e os apoios" a modelos escolares, sugerindo "voltar ao funcionamento interno dela (da escola)" (JULIA, 2001, p. 12), apontando instigantes possibilidades de pesquisa nesse campo, tais como: a) normas e finalidades que regem a escola, b) papel da profissionalização docente, c) conteúdos e práticas escolares (JULIA, 2001, p. 19), d) inculcação do habitus (cristão, cívico), e) transferências culturais e f) marcas deixadas pela escola nos indivíduos (JULIA, 2001, p. 36-37).

Contudo, para as pretensões desse artigo, entendo que a proposição de Antonio Viñao-Frago (2007) seja mais adequada, pela abrangência que compreende:

Conjunto de teorias, ideias princípios, normas, modelos, rituais, inércias, hábitos e práticas (formas de fazer e pensar, mentalidades e comportamentos) sedimentadas ao longo do tempo em forma de tradições, regularidades e regras de jogo não interditas e compartilhadas por seus atores, no seio das instituições educativas. Tradições, regularidades e regras do jogo que se transmitem de geração em geração e que proporcionam estratégias. (...) A cultura escolar seria, em síntese, algo que permanece e dura; algo que as sucessivas reformas só arranham ao de leve, que a elas sobrevive, e que constitui um sedimento formado ao longo do tempo. Um sedimento 
configurado, isso sim, por capas mais mescladas do que sobrepostas que, em jeito arqueológico, é possível desenterrar e separar (VIÑAO-FRAGO, 2007, p. 87).

Esse autor aponta as regularidades que se sedimentam como tradições que tendem a se perpetuar, inercialmente, transmitidas através das gerações dos "atores" escolares, constituindo assim uma cultura na forma de rituais, comportamentos, modos de pensar e agir, normas e costumes, tão característicos das instituições escolares.

Também identifica os elementos da referida cultura e os diferentes aspectos implicados que interferem em sua conformação e dinâmica característica: a) atores (professores, alunos, pais, administração e serviços) e sua formação, idade, representações, composição social, carreira acadêmica, etc.; b) "discursos, linguagens, conceitos e modos de comunicação" utilizados no meio escolar; c) aspectos organizativos institucionais (práticas e rituais, formas de classificação e avaliação de alunos, organização curricular, hierarquias, organização e usos do tempo e do espaço, etc.) e d) "cultura material da escola, seu entorno físicomaterial e objetos (espaços edificados e não edificados, mobiliário, material didático)" (VIÑAO-FRAGO, 2007, p. 88-89). Do cruzamento dessas variáveis e de sua dinâmica de mudanças resulta que seria mais apropriado falar em culturas escolares, no plural, uma vez que "cada estabelecimento docente tem, de forma mais ou menos acentuada, a sua própria cultura, as suas características peculiares, (...) embora entre eles se possam estabelecer semelhanças, (...) traços culturais, estáveis e persistentes" (VIÑAO-FRAGO, 2007, p. 95). Para esse historiador, afinando ainda mais nossa percepção sobre o universo escolar:

Há, pois, culturas específicas de cada centro docente, de cada nível educativo e de cada um dos grupos de actores que intervêm na vida quotidiana das instituições de ensino, assim como subculturas específicas. Mas essas instituições não operam no vazio. Actuam dentro de um enquadramento legal e de uma política determinada que tem sua própria cultura (VIÑAO-FRAGO, 2007, p. 97).

Desse modo, ampliam-se substancialmente as possibilidades de pesquisa, observação, compreensão e análise da realidade escolar ao professor de História ou ao futuro professor em processo de formação, pelo estranhamento frente aos diferentes sujeitos escolares, investigando sua diversidade de características, 
tais como faixa etária, condição socioeconômica e étnico-racial, gênero e nível de estudo, que interferem diretamente nas representações sobre o próprio ato educativo, o papel da escola e a importância atribuída à disciplina História e ao conhecimento histórico, configurando, consequentemente, a cultura escolar. Também são aspectos constituintes e constituidores desse processo, os jargões característicos da escola e das diferentes disciplinas escolares, os sinais e os cartazes, os gestos, as formas de oralização e os códigos implícitos e explícitos presentes nas relações entre os diferentes sujeitos. Ainda se observam a organização e os usos do espaço e do tempo, as diversas práticas das diferentes disciplinas e a hierarquia entre elas, os vários rituais cotidianos e as celebrações, as regras disciplinares e a organização didática da aula. Finalmente, cumpre atentar para os aspectos físicos da escola, com seu mobiliário e os materiais didáticos, a estrutura arquitetônica das salas, corredores, pátios, biblioteca, áreas de circulação, jardins, seus usos, ocupações e modificações interpostas.

Projetar no ensino de História, na acepção aqui proposta, supõe por imprescindível que se compreenda a cultura escolar e seus elementos, sob a pena de transformar essa disciplina em algo anódino, em que conteúdos e abordagens são padronizados por supor haver homogeneidade entre as escolas e os diferentes sujeitos que nela atuam, como querem fazer crer aqueles que propugnam haver "aprendizagens essenciais ${ }^{2}$ que todos os alunos devem desenvolver", escamoteando o fato de que o currículo implica seleção, que "selecionar é uma operação de poder" (SILVA, 1999, p. 16) e que tal operação está implicada nas relações sociais (SILVA, 1996, p. 164) que são desiguais e definem "qual conhecimento é legítimo e qual é ilegítimo, (...) quais vozes são autorizadas e quais não o são (...) quais grupos sociais podem representar a si e aos outros e quais grupos sociais podem apenas ser representados ou até mesmo serem excluídos de qualquer representação". (SILVA, 1996, p. 166).

É interessante notar que na referida obra de Viñao-Frago (2007), em que analisa as reformas educativas ${ }^{4}$ efetuadas no século XIX e XX, notadamente na Espanha, observa que nem sempre logram êxito, pelo contrário:

2 Grifo do original.

3 Disponível em: http://basenacionalcomum.mec.gov.br/abase/\#introducao. Acesso em: 13 jan. 2019.

4 Por reforma educativa, Viñao-Frago (2007) entende: alteração das políticas educacionais nacionais "que pode afetar o governo e a administração do sistema educativo e escolar, a sua estrutura e financiamento, o currículo - conteúdos, metodologia, avaliação - o professorado - formação, selecção ou avaliação - e a avaliação do sistema educativo" (p. 108). 
As reformas fracassam não já porque, como é sabido, pelo facto de todas elas produzirem efeitos imprevistos, indesejados e inclusivamente opostos aos procurados; não já porque originam movimentos de resistência, não encontrem os apoios necessários ou não acertem na implicação do professorado na sua realização; não já porque, ao serem aplicadas, se convertem num ritualismo formal ou burocrático, mas antes porque, em virtude da sua própria natureza a histórica, ignoram a existência desse conjunto de tradições e regularidades institucionais sedimentadas ao longo do tempo, de regras do jogo e pressupostos repartidos, não interditados, que são os que permitem aos professores organizar a atividade acadêmica, conduzir as aulas e, dada a sucessão de reformas ininterruptas que se concretizam a partir do poder político e administrativo, adaptá-las, por intermédio de sua transformação, às exigências que se derivam de tal cultura ou gramática (VIÑAO-FRAGO, 2007, p. 101).

Tais fracassos decorreriam, portanto, da ação deliberada ou desavisada dos reformadores de ignorar as culturas escolares e seus diferentes elementos: sujeitos diversos, organização, rituais, hierarquias, regras, organização do espaço, discursos próprios, representações, práticas.

\section{Relatos sobre a cultura escolar}

Instados a observar a cultura escolar, discutindo os elementos acima citados com o propósito de identificar e analisar aspectos específicos e significativos da referida cultura em unidades escolares estagiadas ${ }^{5}$ durante curso de Licenciatura em História ${ }^{6}$, como o intuito de produzir relatórios e projetos de interação ${ }^{7}$,

5 As escolas estagiadas aqui referidas pertencem à rede pública estadual de São Paulo, todas localizadas na cidade de Guarulhos, Grande São Paulo, sendo 11 Unidades Escolares estagiadas em 2012 e 19 estagiadas em 2014.

6 O estágio é atividade prevista no curso de Licenciatura em História da Universidade Federal de São Paulo, conforme legislação em vigor, dentro das Unidades Curriculares (disciplinas): "Ensino de História: Estágio e Pesquisa" (1 ${ }^{\circ}$ semestre), "Ensino de História: Estágio e Metodologias" ( $2^{\circ}$ semestre) e "Ensino de História: Estágio e Práticas" ( $3^{\circ}$ semestre).

7 Os Relatórios de Estágio e Projetos de Interação aqui utilizados como fonte documental são o resultado final de longo processo de observação, produção de relatos parciais e debates ocorridos durante três semestres de duas turmas de graduandos (vespertino e noturno), por mim acompanhadas, concluintes nos anos de 2012 (84 alunos) e 2014 (68 alunos). Para esse artigo foram consultados 67 documentos, entre Relatórios, Projetos e eventuais anexos, produzidos em grupo por essas duas turmas nos anos mencionados. 
os, então, estudantes agora graduados, alguns deles já atuando como professores, revelaram em sua produção a argúcia e a minúcia no olhar de estranhamento sobre a realidade escolar. Ademais, apontaram para possibilidades fecundas de construção de projetos nessa disciplina ou em modo interdisciplinar, aspectos que aqui discutiremos.

A modalidade de registro documental aqui usada, relatórios de estágio de alunos de Licenciatura em História, também foi utilizada como fonte em pesquisa realizada no final dos anos 1990 quando discuti o ensino de História durante a ditadura militar brasileira (ALMEIDA NETO, 1996). Naquela ocasião foram pesquisados relatórios de alunos da Licenciatura em História da Faculdade de Educação da Universidade de São Paulo, FEUSP, entre 1972 e 1979, sob a responsabilidade da Prof. ${ }^{a}$ Elza Nadai.

Considerei (e considero) que tais relatórios se constituíam como fonte documental privilegiada para discussão da cultura escolar, seja pelo ineditismo, seja por informarem vários aspectos da vida escolar: alunos, direção, livro didático, processo educativo, dinâmicas de funcionamento, rotina, procedimentos, além de depoimentos dos diferentes sujeitos escolares e aspectos sobre a estrutura hierárquica (ALMEIDA NETO, 2010, p. 157). Ressalte-se que:

Os estagiários são observadores que estabelecem relações ambíguas com os professores. Há, por exemplo, mudanças nas atitudes dos professores quando da presença do estagiário na classe. Entretanto o estagiário parece ter mais proximidade com os alunos, que o consideram, muitas vezes, como um cúmplice, pois sabem que ele acaba sendo um avaliador do professor. Tais características imprimem aos relatórios uma qualidade especial como documento de pesquisa. Diferentemente das demais fontes utilizadas, essa apresenta uma informalidade advinda de um olhar mais despretensioso do observador, contando com relativa neutralidade em relação ao objeto observado e, até mesmo, certa objetividade pelo cumprimento de uma tarefa obrigatória para o curso de licenciatura (ALMEIDA NETO, 2010, p. 158).

Destaco agora, nesse artigo, alguns excertos de relatórios que se mostram especialmente densos de conteúdo crítico, como, por exemplo, um deles que ao analisar as formas de apropriação do espaço escolar destaca a profusão de símbolos religiosos cristãos na forma de grafites, imagens, faixas, estátuas e músicas e o impacto que esses elementos provocam sobre o processo de formação dos alunos, particularmente o efeito persecutório sobre aqueles que congregam religiões de matriz africana: 
A escola $\mathrm{A}^{8}$ é carregada de imagens religiosas da Igreja Católica, em seus muros e paredes internas, feitas com a técnica de grafite. A comunidade escolar é muito religiosa como já foi notado em diversas aulas oferecidas desde fevereiro. Notamos preconceito com outras religiões como as de matriz africana; mães e alunos reivindicando não falar de religião em sala de aula, numa contradição e falta de entendimento do que seja Estado laico, por conta das imagens de Jesus e de santos dentro da escola; faixas presas às grades da escola ao lado [escola $\mathrm{B}$ contígua à escola $\mathrm{A}$ ], fazendo chamada para uma "Cruzada evangelística"; e reprodução de músicas de grupos religiosos, tocadas no violão, mostradas em sala de aula e nos

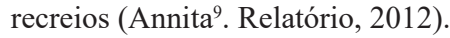

Esse registro conflui para o que afirma Escolano (2001), segundo quem a arquitetura escolar "pode ser vista como um programa educador, ou seja, como elemento do currículo invisível e silencioso, ainda que ela seja, por si mesma, bem explícita ou manifesta (...) seus elementos simbólicos próprios ou incorporados e a decoração exterior ou interior" (ESCOLANO, 2001, p. 45). A referida aluna observou com precisão que tais símbolos não são apenas elementos inofensivos da paisagem, mas possuem um efeito educador, constituindo-se como currículo, formando alunos dentro de determinados valores e padrões culturais religiosos que, internalizados pelos diferentes sujeitos, acabam sendo naturalizados.

Também com relação ao espaço escolar, porém no que se refere à sua organização e seus usos, registrou-se seu papel no disciplinamento dos alunos e pais pelo cerceamento de sua circulação e dos professores pela vigilância da sua prática em sala de aula. O mesmo foi observado sobre a utilização do vestuário específico dos alunos em flagrante contradição com o discurso pedagógico veiculado pelos gestores e professores:

Enquanto os discursos em torno da liberdade e da inclusão foram constantes nos discursos da equipe gestora da escola e na fala de alguns professores, podemos ver seu contrário na arquitetura escolar, na fiscalização das aulas dos professores, na obrigatoriedade dos uniformes, na exigência de uma espécie de "salvo-conduto" para que o aluno possa sair da sala em horário de aula (que traz a identificação do professor responsável), na restrição à presença da comunidade circundante na escola (ainda que 
negada pela direção) e, na prática, ainda que velada, da segregação, ao lançar os alunos indisciplinados, repetentes, ou considerados de alguma forma indesejáveis numa mesma turma (Deividi, Elson, Evandro, Felipe e Isis Relatório, 2012).

Observe-se o alcance da normalização tão característica da forma escolar, que se impõe sobre todos os sujeitos escolares como "regras supra-pessoais" (VINCENT; LAHIRE; THIN, 2001, p. 30), atingindo não só os alunos, mas os pais, os professores e também os chamados gestores, o que torna o poder um exercício impessoal que se impõe pelo cumprimento de regras as quais todos devem, por fim, obedecer e internalizar.

Um aspecto notado com muito destaque foi o das representações dos diferentes sujeitos escolares sobre si mesmos e entre si, sobre a própria instituição escolar e seu papel e sobre as disciplinas escolares:

\begin{abstract}
Desse modo, evidencia-se uma representação por parte dos professores em relação aos alunos e os veem como classes populares que devem ser retiradas do convívio da rua, cuja ação é vista como trágica, por meio da ocupação sistemática. (...) Nesse sentido, os professores atribuem aos seus trabalhos realizados um sentido quase que missionário. Vendo seus alunos como seres propensos à "bandidagem", à promiscuidade e indolência, esses profissionais tentam por em prática um discurso extremamente preconceituoso. Acreditam que a função de suas aulas é "salvar" seus discentes, pelo menos uma pequena parte deles, de um futuro tenebroso, de crimes e degradação social (Carlos, Fabio, Felipe e Guilherme. Relatório, 2012).
\end{abstract}

Tais representações, por vezes, expressam situações de extrema violência entre os diferentes sujeitos, situação que acaba por naturalizar momentos de extrema tensão e agressividade, observadas na organização do espaço e desdobrando-se particularmente nos discursos proferidos sobre os alunos:

Discursos acentuados, e que se contrapõem, estão presentes tanto na espacialidade da instituição como na prática docente. Esses discursos/representações se referem aos alunos e seu comportamento dentro da instituição. Marcados por características de violência e incapacidade intelectual dos alunos, essa representação (e discursos) acaba por influenciar a realidade 
da escola, tendo reflexos no próprio ensino oferecido pela escola $\mathbf{D}$ e criando muitas vezes um ambiente de tensão entre professores e alunos. Esta representação sobre "o outro", neste caso, os alunos, é percebida através das falas de professores, coordenadores e funcionários da instituição. É um olhar sobrecarregado por um discurso de violência e marginalidade, que, consideramos estar intimamente ligado à condição socioeconômica, de acordo com a análise feita pela instituição, da comunidade onde a escola se insere (Marcelo, Michele, Nara e Otávio. Relatório, 2014).

Essa situação acaba por revelar sua face mais perversa numa análise da cultura escolar explícita as representações de um grupo de alunos sobre si mesmos como sendo a escória da sociedade, estando fadados ao fracasso, numa espécie de profecia que se auto cumpre:

Por ser vista como uma escola de má qualidade por moradores do bairro, professores, gestores e alunos, há uma grande evasão estudantil e profissional. Há uma percepção de que todos os alunos são vinculados ao tráfico de drogas ou violência, direta ou indiretamente (através da família ou conhecidos, por exemplo). Sabendo dessa imagem, os próprios alunos referem-se a si mesmos como "lixos" e "maus alunos" (André, Carlos, Gabriel, Juliana e Mauricio. Relatório, 2014).

A análise torna-se relevante se considerarmos, como Lefebvre, que as representações não se constituem como elemento a ser superado ou transcendido por ser considerado ilusório, irreal ou errado, mas como possuidoras de grande força na sociedade - haja vista a força da publicidade. Assim, entende que “(...) as representações não são falsas nem verdadeiras, senão, às vezes, falsas ou verdadeiras: verdadeiras como respostas a problemas 'reais' e falsas como dissimuladoras das finalidades 'reais'.” (LEFEBVRE, 2006, p. 68) e, portanto, deveria a teoria crítica das representações "expor o poder da representação no mundo contemporâneo, deslindar os mecanismos de sua produção e permanência" (LUTFI; SOCHACZEWSKI; JAHNEL, 1996, p. 96), sem a ilusão de destruí-las ou rechaçá-las.

$\mathrm{Na}$ observação da busca pela ordem, foi registrado a ênfase no discurso disciplinar acompanhado do rígido controle do comportamento em todos os momentos e circunstâncias da vida escolar, ainda que velhas práticas escolares tenham sido eventualmente abandonadas, de modo que pela insistência e 
repetição, "ao compreender as regras, o aluno se apropria delas por si mesmo e pratica uma espécie de autodisciplina, um 'self-government" (VINCENT; LAHIRE; THIN, 2001, p. 33):

O discurso de manutenção da ordem se faz hegemônico no cotidiano desta unidade escolar. Se não se enfileira mais as crianças no pátio para que cantem o hino nacional e ouçam as regras de conduta da escola, tais regras não deixam de ser verbalizadas todos os dias, nos mais diversos momentos. Inícios de aula são constantemente atrasados, aulas são interrompidas ou atividades substituídas por broncas ministradas pelos professores. Visitas da coordenadora e da professora mediadora de conflitos são frequentes para lembrar aos alunos a importância das regras e as consequências de seu descumprimento. "Quem não se encaixar a ordem que procure outra escola", "tem muita gente lá fora querendo vaga nesta escola", "aqui se prima pelo preparo de bons profissionais para o mercado de trabalho", "quem não produzir não tem que ficar aqui", "aqui é lugar de aluno que produz", "as regras são claras e as consequências também", são algumas das tantas frases que são repetidas todos os dias à exaustão para os alunos que, por sua vez, reclamam da quantidade de broncas, mas reconhecem a importância delas quando assumem preferir está à outra unidade escolar da região, quando se dizem satisfeitos e orgulhosos por estudarem numa unidade escolar "bonita e organizada", na qual as coisas "funcionam de verdade" (se referindo à sala de vídeo, bibliotecas e outros espaços). (Bruna, Carla, Evelyn e Samuel. Relatório, 2014).

Também no registro das representações, foi observado o que poderíamos chamar de representações da excelência escolar:

A. A partir de diversas visitações e reflexões foi possível identificar que na escola $\mathbf{C}$ se constrói uma noção patente a respeito da própria escola. Para os que a frequentam - sejam alunos, professores, e diversos outros funcionários - não se trata de uma simples e qualquer escola, e sim de uma escola excepcional, a melhor da região, digna de orgulho de seus mais diversos frequentadores. (...) Nesse sentido, esse discurso aparenta não possibilitar a construção de uma autocrítica sobre a mesma, ocultando, assim, problemas como indisciplina, descompromisso de professores e funcionários e, de maneira geral, as condições materiais do ambiente (Antonio, Rafael,Thiago e Thaís. Relatório, 2012). 
B. Em diversos momentos, seja por meio do discurso hierárquico da direção da escola e dos funcionários, das falas dos professores ou dos alunos, é notável como a escola $\mathbf{E}$ se enxerga em relação ao ensino público de modo geral. Por meio desses três níveis de articulação [professores, funcionários e alunos] é conduzido um discurso coerente acerca da cultura escolar de "instituição modelo". (...) Os estudantes reforçam a noção da "escola modelo" ao discorrem sobre seus longos trajetos até a chegada a instituição e as dificuldades enfrentadas por seus familiares para conseguirem uma vaga na escola. Para os estudantes, essa instituição "modelo" é a antítese de suas vivências em escolas nos bairros dos quais proveem e adentrá-la é um processo que envolve uma notável circulação de ideias a respeito da "fama" da escola, muitas vezes por meio das apreciações realizadas por outros colegas. Cabe observar, no entanto, que o discurso dos estudantes é aquele que revela as maiores contradições, uma vez que as vivências escolares muitas vezes não correspondem às expectativas sobre a "escola modelo". Nesse sentido, diferentemente do que ocorre em outros níveis do discurso, é por meio dos relatos dos estudantes que os problemas da instituição tornam-se tangíveis (Ana, Celeste, Jonathan, Lucilayne, Patrícia e Tatiane. Relatório, 2014).

Observe-se aqui a aguda percepção dos estagiários sobre a força das representações, nesse caso da "excelência" da instituição de ensino, ao dissimular a realidade obliterando a consciência das precariedades manifestas no descompromisso, indisciplina, condições materiais. Apontam ainda a circulação dessas representações que acaba funcionando como mecanismo de reprodução das mesmas, alimentando o desejo e esforço dos diferentes sujeitos, particularmente, alunos e professores, para serem incorporados a essa instituição "modelo", tida como superior às demais escolas públicas estaduais da região.

Finalmente, entre os registros feitos pelos estudantes de História, destacase a percepção da cultura escolar como "produto histórico" (VIÑAO-FRAGO, 2007, p. 93), portanto, cambiante entre mudanças e permanências. As mudanças, nesse caso, deveram-se a alteração do perfil dos alunos frequentadores, certamente decorrente de mudanças conjunturais, com desdobramentos na organização e usos do espaço e na percepção existente sobre a escola:

A escola estagiada passa por uma crise de identidade, uma vez que, anteriormente, se tratava de um colégio do bairro, que atendia as crianças e jovens residentes nas redondezas da escola, configurando-se como uma instituição presente e bem-quista pelos moradores locais. Enquanto estagiamos, não encontramos mais essa realidade, pois, a maioria dos 
alunos que estudam atualmente na escola vem de outras localidades, sobretudo do Pimentas [bairro de Guarulhos]. À vista disso, percebemos que por ter deixado de exercer a função que tinha para os moradores do bairro, o colégio tornou-se um peso para a comunidade, uma vez que a movimentação de jovens estranhos ao local seria, sobretudo, por causa da escola. Por conta disso, conforme a coordenadora Monica nos alertou, o colégio foi sendo gradeado e isolado do resto do bairro, o que nos permite concluir que essa relação se reflete até na arquitetura escolar da instituição (Bruna, Giorgia, Juliana, Michele e Olívia. Relatório, 2014).

Dada a profusão de possibilidades dessa fonte documental, retorno, nesse artigo, aos relatos de estágio, reafirmando o propósito do entendimento da cultura escolar, informada pelos relatórios de dois grupos de estudantes (2012 e 2014), para percepção da educação e do ensino de História como campo de pesquisa e importante ferramenta na construção de projetos para essa disciplina escolar, aspecto que discutirei a seguir.

\section{Projetos para a cultura escolar}

Nesses relatórios, tomados aqui como fontes documentais, os graduandos partiam da proposta de considerar a(s) especificidade(s) dos elementos da cultura escolar do local onde fora realizado o estágio de Licenciatura em História, percurso que transcorre ao longo de três semestres, com sucessivos estudos, idas a campo, pesquisa de observação, análise de registros escolares, entrevistas, debates, relatórios, pré-projetos e elaboração de projeto de interação na disciplina escolar História, ou em modo interdisciplinar, que emergisse dessa realidade e se voltasse para ela, considerando aspectos como tema, conteúdos, série/ano, faixa etária, materiais e recursos didáticos, metodologia, cronograma e abordagem. Na definição precisa de alguns estudantes:

O objetivo do projeto não se centra na intenção de evidenciar ou mesmo exercer juízos de valor a respeito das características culturais identificadas, pretendemos, ao invés disso, colocá-las em uma perspectiva histórica, identificando-as com contextos mais amplos e, desse modo, buscar estimular reflexões acerca destas no cotidiano escolar (Antonio, Rafael,Thiago e Thaís. Projeto, 2012). 
Vejamos alguns excertos desses projetos. Um dos grupos de estudantes, que havia destacado a relação da organização do espaço escolar com seu entorno, uma vez que a cultura escolar é "uma combinação submetida à lógica de tais regularidades [institucionais] e à pressão de aspectos externos à mesma" (VIÑAO-FRAGO, 2007, p. 93), observou a forte influência do processo de industrialização local sobre a escola:

De todos os aspectos dessa cultura escolar o que mais nos chamou atenção foi com relação à arquitetura, que é também um constructo cultural que expressa e reflete, para além de sua materialidade, determinados discursos. A construção e a espacialização da escola mostram que existe uma série de relações de poder expressas nela. A primeira se deve à estrutura que segue o modelo do panóptico, o que causa a constante sensação de vigilância para o controle não só dos alunos, mas também da prática dos professores e funcionários desta. A segunda é a quantidade de espaços não acessíveis a estes alunos, com a separação por grades, que deixam claro os ambientes de cada ator, além do constante controle de sua circulação. (...) Para além da própria construção da escola devemos considerar seu entorno. (...) A influência das indústrias além de estar presente nos objetivos da escola e dos alunos, na construção do currículo, pode ser percebida também na arquitetura da escola, que se parece muito com a das fábricas, o que nos permite observar as divisões que expressam relações de poder (Hennan, Janaína, Paola, Philippe, Renata e Talita. Relatório, 2012).

Assim, propuseram em seu projeto, intitulado Trabalho Industrial, "trabalhar com os alunos a industrialização da cidade de Guarulhos, relacionada ao aspecto desenvolvimentista da passagem da primeira para a segunda metade do século XX no Brasil. Marcada pela industrialização e urbanização" (Hennan, Janaína, Paola, Philippe, Renata e Talita. Projeto, 2012).

O tema da organização disciplinar da escola associada aos mecanismos de controle e de exclusão suscitou noutro grupo a necessidade de problematizar a concepção de disciplina e suas implicações:

Para proporcionar um debate a respeito do tema proposto, procuraremos focar na questão da exclusão pelo espaço, desnaturalizando-o, uma vez que este pode ser projetado para servir ao disciplinamento e ao controle das pessoas e da sociedade, de modo geral. Utilizaremos diferentes temporalidades, locais e conteúdos: a exclusão e segregação por meio dos espaços e das práticas no Apartheid na África do Sul (1948-1992); a formação dos 
guetos estadunidenses (1930-1980); a questão das favelas em São Paulo na contemporaneidade; e outros casos de exclusão e segregação presentes na sociedade (Alessandra, Edsonia, Renata e Verônica. Projeto, 2012).

É importante destacar que o grupo em questão optou por um rol de conteúdos que transita por diferentes temporalidades históricas e espaços, sem que se incorra no pecado do anacronismo histórico, tão comum em abordagens semelhantes.

Já o grupo que observou o que denominamos de "representações da excelência", propôs resolver o problema dos anacronismos pelo questionamento da própria construção do conhecimento histórico, que decorre de escolhas das fontes documentais e das abordagens metodológicas. Como sugestão esse grupo apresentou a discussão da chamada Guerra Fria encaminhada a partir de uma História em Quadrinhos, Watchmen ${ }^{10}$, um clássico da graphic novel escrito por Alan Moore:

Nosso objetivo é discutir em sala de aula particularmente o conceito de "Destruição Mútua Inevitável" a partir de elementos tratados em Watchmen. O conceito, que se relaciona ao potencial bélico dos países envolvidos no contexto do pós-guerra, é contextualizado por Hobsbawm ao discorrer sobre como enquanto os EUA temiam o "perigo de uma possível supremacia soviética num dado momento futuro", a Rússia se preocupava com "hegemonia de fato dos EUA, então exercida sobre todas as partes do mundo não ocupadas pelo Exército Vermelho". (...) a) Problematizar a noção de fonte histórica e apresentar a multiplicidade de abordagens em relação aos materiais que podem ser utilizados para uma discussão histórica; b) Possibilitar ao estudante uma compreensão sobre como os discursos e as representações são construídas pelos diferentes lados de um determinado embate (Ana, Celeste, Jonathan, Lucilayne, Patrícia e Tatiane. Projeto, 2014).

A mesma questão da "excelência", tratada por outro grupo de graduandos, 2 anos antes, também propôs a utilização de conteúdos sobre a Guerra Fria, porém atualizando o debate, inserindo o tema dos atentados de 11 de setembro de 2001 nos EUA:

10 MOORE, Alan; GIBBONS, David. Watchmen. SP: Editora Panini Livros, 2009. 
Foram pensadas temáticas históricas que permitam levantar questões relacionadas a situações em que determinados discursos são alçados como "excepcional" em oposição a discursos tidos como "medíocres" e "inferiores" no correr da História. Desse modo, trabalhar-se-á com a noção de tempo histórico a partir da construção e embasamento desses discursos de excepcionalidade. Assim, tendo-se em vista as aulas que foram disponibilizadas para a aplicação deste projeto, optou-se pelas temáticas da Guerra Fria e dos desdobramentos políticos e culturais dos atentados de 11 de setembro de 2001, pois, tais fenômenos possibilitaram a construção de discursos de excepcionais antagônicos (Antonio, Rafael, Thiago e Thaís. Projeto, 2012).

No que se refere às representações sobre "o outro" e, consequentemente, sobre "si mesmo", numa escola com grande número de alunos de origem nordestina e bolivianos, esse aspecto foi definidor para escolha do tema - Migração Nordestina: construção e desconstrução das representações - e do projeto de interação que propôs problematizar o conceito de "paulistanidade" e a noção de identidade, pensando historicamente diferentes movimentos migratórios e suas implicações:

O tema será desenvolvido em dois eixos principais: o primeiro, sobre a migração no final da década de 1930, dando atenção à migração rural para São Paulo, e nas décadas de 1950 e 1960, quando os deslocamentos tem como destino a cidade de São Paulo, especificamente o bairro de São Miguel Paulista. O segundo eixo aborda a ideia de "paulistanidade" para pensarmos como os nordestinos eram vistos e assumiram na cidade a figura "do outro". (...) Questões sobre a identidade nacional tangenciarão as discussões, principalmente no que se refere ao conceito de "paulistanidade". Neste ponto, ressaltaremos a influência e identidade europeia, advinda igualmente de descolamentos e migração, escolhida pelos paulistas. O objetivo é mostrar como se dão essas construções de identidade e pensar como elas constituem um discurso e uma representação, esta que é internalizada pelos paulistas, e que não estão apenas no plano do imaginário, mas alteram e transformam a realidade das pessoas na cidade. Dessa maneira, por meio da análise dos deslocamentos internos e externos de pessoas para São Paulo, pretendemos que os alunos consigam identificar essas construções e pensá-las de modo desnaturalizado (Marcelo, Michele, Nara e Otávio. Projeto, 2014). 
Numa das escolas já mencionadas, foram registrados alguns flagrantes de discursos obtidos em breves conversas com um professor de História e dois alunos do $1^{\circ}$ ano do Ensino Médio: "Sabe aquele grupo ali, de escurinhos? Não tem como explicar, não ficam quietos"; "Essa professora é meio 'monga', fica falando e falando..."; "Quando eu entro na escola é como se eu estivesse entrando na cadeia, aqui só tem grade e portão". É a mesma instituição em que alunos se autodenominaram "lixos" e "maus alunos". Diante desse quadro, o grupo de estudantes de História considerou que a violência tornou-se elemento naturalizado corroendo as relações entre os diferentes sujeitos escolares, sendo elemento definidor da cultura escolar. Assim, construíram um projeto que propunha discutir a ditadura civil-militar brasileira observando os diferentes tipos e níveis de violência, bem como as formas de resistência:

Para o desenvolvimento das questões propostas [dentro do conteúdo ditadura civil-militar brasileira, em acordo com a professora estagiada], optou-se pela utilização de fontes de diversos tipos (imagens, relatos, notícias, músicas e afins), as quais evidenciam diferentes maneiras de apreender as problemáticas do passado. Elegeu-se, para tanto, três eixos de abordagem: violência institucionalizada (por meio de prisões, torturas, assassinatos, censura), violência de viés econômico (desigualdade social, condições de trabalho) e, por fim, a resistência (luta armada, atuação parlamentar e cultural). (André, Carlos, Gabriel, Juliana e Mauricio. Projeto, 2014).

Os projetos aqui apresentados trazem não só possibilidades de seleção de conteúdos que sejam significativos para os alunos, por dialogarem com a cultura escolar, como apontam para uma diversidade de abordagens, o que se coaduna com a formação do historiador, que está longe de ser a da reprodução alienada dos conhecimentos produzidos por outrem. Também sugerem uma multiplicidade de abordagens que transitam em diferentes temporalidades históricas e espaços, não necessariamente lineares. Finalmente, não dispensam a utilização de diferentes materiais didáticos (fotografia, pinturas, charges, filmes, documentos históricos, HQs, músicas, literatura), além dos livros didáticos, e a reflexão sobre a arquitetura escolar, sob a compreensão teórica de que pensar o currículo envolve não só o debate sobre as disciplinas escolares, conteúdos, suas implicações sociais e políticas, mas também os aspectos metodológicos, as atividades da prática, a organização do espaço físico, os projetos pedagógicos em sua dinâmica (MOREIRA, 1998). 
Tais possibilidades aqui assinaladas apontam para um professor de História, em formação ou já exercendo atividade docente, que objetiva proceder à reflexão histórica, que não se reduz e nem quer ser reduzido à condição de mero executor de tarefas que visam padronizar e uniformizar o currículo e o conhecimento. Um profissional de História que, justamente pelo conhecimento de sua área, se apraz em projetar, realizar a obra criativa e criadora, condição para emergir de um cotidiano escolar que se apresenta cada vez mais programado. Da mesma forma, a discussão da cultura escolar, nesse contexto, se apresenta como importante disparador (certamente, não o único) para as reflexões que não se coadunam com proposições alienígenas desconectadas da realidade escolar.

\section{REFERÊNCIAS}

ALMEIDA NETO, Antonio Simplicio de. Ensino de história e cultura escolar: fontes e questões metodológicas. Revista Brasileira de História da Educação, n. 22, p. 141-167, jan./abr. 2010.

ARGAN, Giulio Carlo. Projeto e destino. SP: Ática, 2004.

BLOCH, Marc. Apologia da História, ou, O ofício de historiador. Rio de Janeiro: Jorge Zahar Ed., 2001.

CHERVEL, André. História das disciplinas escolares: reflexões sobre um campo de pesquisa. In: Teoria \& Educação, n. 2, 1990.

CHEVALLARD, Yves. La transposición didáctica: del saber sabio al saber enseñado. Buenos Aires: Aique Grupo Editor, 2005.

ESCOLANO, Agustín. Arquitetura como programa. Espaço-escola e currículo. In: VIÑAO-FRAGO, Antonio; ESCOLANO, Agustín. Currículo, espaço e subjetividade: a arquitetura escolar como programa. RJ: DP\&A, 1998.

FARIA FILHO, Luciano M. de; GONÇALVES, Irlen A.; VIDAL, Diana G.; PAULILO, André L. A cultura escolar como categoria de análise e como campo de investigação na história da educação brasileira. Educação e Pesquisa, São Paulo, v. 30, n. 1, p. 139-159, jan./abr. 2004.

FORQUIN, Jean-Claude. Saberes Escolares, Imperativos Didáticos e Dinâmicas Sociais. Teoria \& Educação. Porto Alegre, v. 5, 1992.

JULIA, Dominique. A cultura escolar como objeto histórico. In: Revista Brasileira de História da Educação, n. 1, p. 9-44, 2001. 
LEFEBVRE, Henri. La Presencia y la Ausencia: Contribuición a la Teoria de las Representaciones. México: Fondo de Cultura Económica, 2006.

LUTFI, Eulina P.; SOCHACZEWSKI, Suzanna; JAHNEL, Teresa C. As Representações e o Possível. In: MARTINS, José de S. (org.). Henri Lefebvre e o Retorno à Dialética. SP: Hucitec. 1996.

MOORE, Alan; GIBBONS, David. Watchmen. SP: Editora Panini Livros, 2009.

MOREIRA, Antonio Flávio B. A didática e o currículo: questionando fronteiras. In: OLIVEIRA, Maria Rita N. S. Confluências e divergências entre didática e currículo. Campinas: Papirus, 1998.

SILVA, Tomaz T. da. Documentos de identidade: uma introdução às teorias do currículo. Belo Horizonte: Autêntica, 1999.

SILVA, Tomaz T. da. Identidades terminais: as transformações na política da pedagogia e na pedagogia da política. Petropólis, RJ: Vozes, 1996.

TOLEDO, Maria Rita de A.; COSTA, Wilma P. Formação docente, História, Memória e Educação Patrimonial: desafios para a produção de novas práticas educativas. In: PAIVA, Odair da C.; LEAL, Elisabete (org.). Patrimônio e História. Londrina: Unifil, 2014.

VIÑAO-FRAGO, Antonio. Sistemas educativos, culturas escolares e reformas. Portugal, Mangualde: Edições Pedago, 2007.

VINCENT, Guy; LAHIRE, Bernard; THIN, Daniel. Sobre a história e a teoria da forma escolar. Educação em Revista, Belo Horizonte, v. 33, p. 7-48, jun. 2001.

Texto recebido em 18/01/2019.

Texto aprovado em 16/04/2020. 